\title{
The UNCTAD Liner Code: a Critical Dissent
}

\section{Anthony Renouf}

The international shipping industry is distinguished from most other transport and many other service industries by the degree to which it has survived four fifths of the 20th century without any significant state intervention on the one hand, and without any oligopolistic concentration of ownership on the other. Shipping companies are thus more exposed to genuine, as against managed, market forces than most other companies trading internationally, and more liable to experience exaggerated peaks of profitability and similar troughs of loss, the past five years being one of the best ever examples of the latter. Liner Conferences exist, of course, but they have not all been effective in stabilising profits. Shipping is, in consequence, the most unlikely candidate for intergovernmental standards of operating practice, and will only bow down to them if enough governments act in detailed concert to outweigh the forces of supply and demand.

\section{The Liner Code In Practice}

The underlying principle of the 1974 UNCTAD Code of Liner Conduct is that each country using ocean-going shipping is entitled to carry an equal per centage of its seaborne trade in ships under its own flag. UNCTAD has chosen shipping because it believes it to be easier to control this service by market-sharing than it would be to make, say, each country with the capacity grow 40 per cent of its own wheat or dig 40 per cent of its own coal consumption. Western shipowners, who at present carry over 80 per cent of 120 developing countries' seaborne trade, agree that ships are easier to move about the world than coal mines and farmland, but claim that this is as far as it goes; creating a right under law to carry cargo does not bequeath upon a country the ability to carry such cargo any more cheaply than foreigners could. Indeed the owners claim that the Code will make it considerably more expensive. And owners registered in countries whose carrying capacity is not used extensively on domestic trade, such as Norway with 8 per cent, Greece with 5 per cent and Liberia with 1 per cent-i.e. the leading cross-traders-see great disadvantage to themselves in multilaterally enforced cargo sharing.
The logic of the Code is somewhat simpler than its practicability: 40 per cent of each and every type of liner cargo is to be carried by ships from the exporting country, 40 per cent by ships from the importing country, and just the remaining 20 per cent by the cross-traders. Since anything between 50 and 100 per cent of some 120 countries' cargoes is at present carried by the ships of 12 countries, it will be seen that a worldwide redistribution of the trade is as much a freight forwarder's nightmare as it undoubtedly must be a UN bureaucrat's dream. But the principle is the thing in international negotiations of this kind.

The key requirement for the Code to come into force was for the countries ratifying it to account for at least 25 per cent of world liner tonnage. This made it effectively impossible for the 120 developing countries to activate it on their own, and essential for at least some of the Western nations to ratify it. There was a tremendous wrangle between the eight shipowning countries of the EEC over ratification, with West Germany - carrying way below 40 per cent of its liner trade-arguing in favour, and Britain-with the capacity to carry 150 per cent of its liner tradearguing against. The compromise that finally allowed the EEC members to agree among themselves, and then to establish a common line with that other major shipowning country, Japan, was ingeniously simple and probably the one that Third World shipping ministries were really after, though they would not care to admit as much.

The compromise is as follows: the 24 countries of the OECD will not operate the 40:40:20 rule in shipping between themselves, but will accept it in trade between each of them and all trading partners from the Third World. Thus the EEC would not demand $\mathbf{4 0}$ per cent of its imports in its own ships from its 17 industrialised colleagues, and would not expect them to do so either. Further, no EEC member country would hang on to its 40 per cent of trade with any Third World state if the line of another EEC member could successfully bid for the business. The formal responses to this from the world's biggest user of shipping, the USA, and the world's biggest supplier and second biggest user, Japan, are expected during 1980; they are expected to 

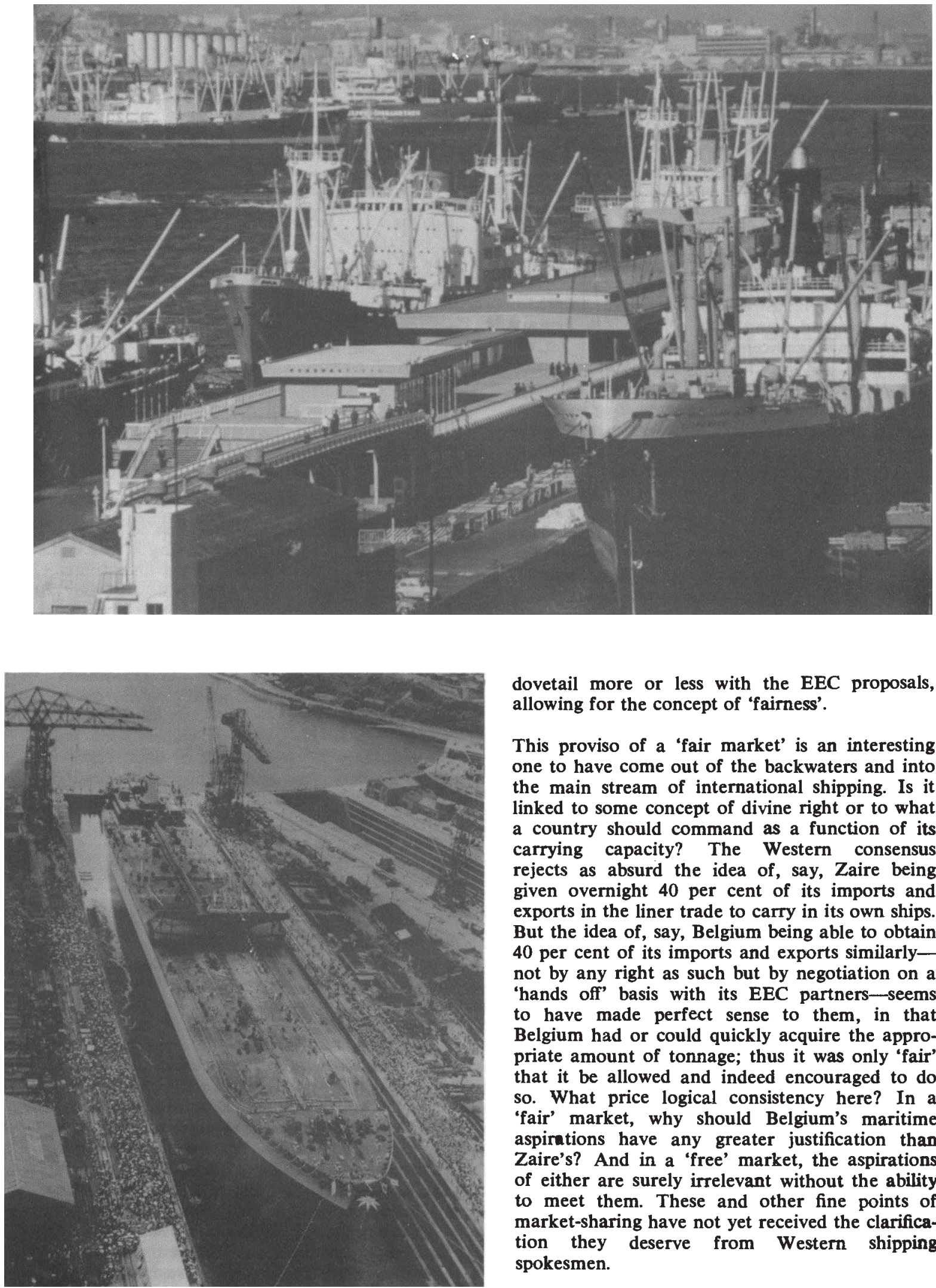

dovetail more or less with the EEC proposals, allowing for the concept of 'fairness'.

This proviso of a 'fair market' is an interesting one to have come out of the backwaters and into the main stream of international shipping. Is it linked to some concept of divine right or to what a country should command as a function of its carrying capacity? The Western consensus rejects as absurd the idea of, say, Zaire being given overnight 40 per cent of its imports and exports in the liner trade to carry in its own ships. But the idea of, say, Belgium being able to obtain 40 per cent of its imports and exports similarlynot by any right as such but by negotiation on a 'hands off' basis with its EEC partners-seems to have made perfect sense to them, in that Belgium had or could quickly acquire the appropriate amount of tonnage; thus it was only 'fair' that it be allowed and indeed encouraged to do so. What price logical consistency here? In a 'fair' market, why should Belgium's maritime aspirations have any greater justification than Zaire's? And in a 'free' market, the aspirations of either are surely irrelevant without the ability to meet them. These and other fine points of market-sharing have not yet received the clarification they deserve from Western shipping spokesmen. 
The reason that Western governments, dragging Western shipowners reluctantly behind them, have taken this great step towards withdrawing a part of world shipping from the market is to prevent its being totally withdrawn, along with shipbuilding, air transport, steelmaking, textiles, and-it is mischievously added-almost everything else. The argument in Brussels, Tokyo and Washington, was that many of the developing countries would act unilaterally if they could not get agreement multilaterally, and would pass laws reserving not 40 per cent of their raw material exports but 50 or 80 per cent. Even though liner ships in fact carry precious few raw materials, and the biggest raw material of them all-crude oil-has not yet been subjected to maritime mercantilism (despite its accounting for two of every three tons carried by sea and originating in only a handful of countries), these considerations did not seem to influence the course of the argument for the compromise acceptance of the Liner Code.

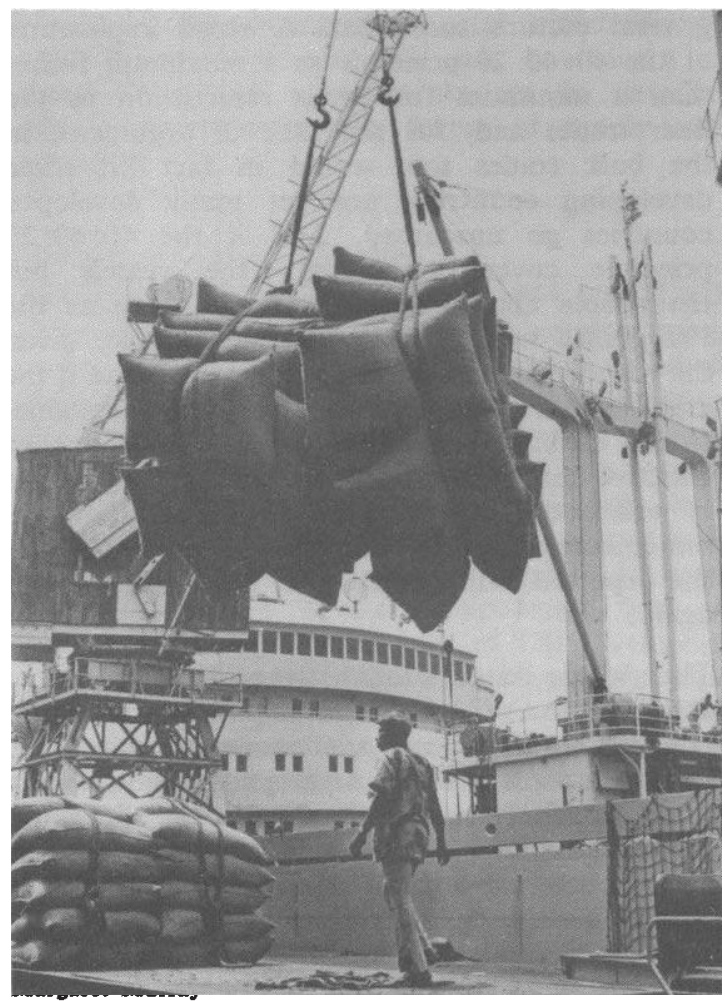

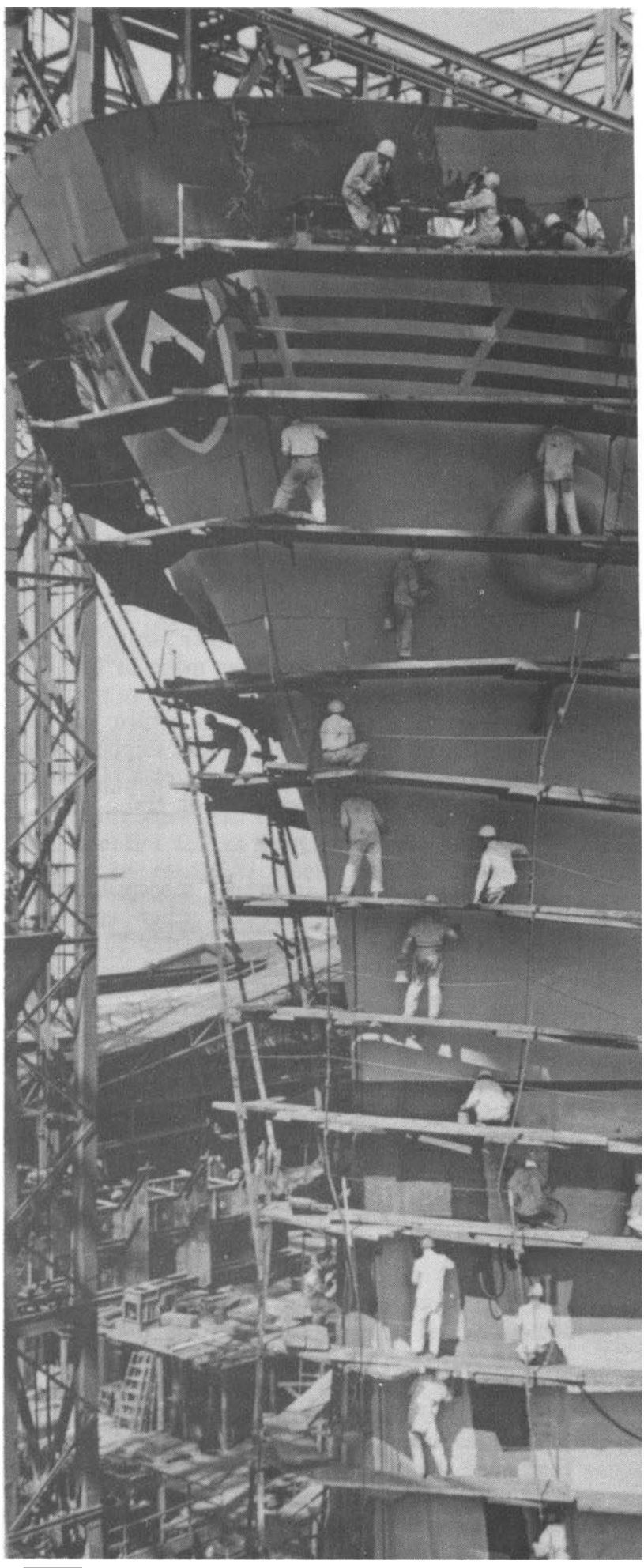

Photographs on pp. 32 and 33 (right)

reproduced with kind permission of the Japan Information Centre, London 


\section{Will Bulk Trade Be Next?}

There are major differences between the bulk and liner trades, which explain the difference of approach. Nightmares of permanent part cargoes for every single ship, and permanent tallies by flag being kept in each and every port, may well now be keeping operations managers of liner companies from their much deserved sleep, but the liner trades are already closely monitored and regulated in ways that the tramp trades are not, if for practical reasons of commerce rather than theoretical reasons of state. A tramp ship can go where it will, but the liner goes where it must. Organised into Conferences, liner ships ply set routes by fairly strict timetables, and are unable to stay in port for a few days on the off chance of topping up with a bit more cargo. Their freight rates, which are set in advance, are common to all the other ships in the Conference, and can be either more or less than the rates they would get on any one day were they operating on a tramp basis. In return for providing a regular service which the shippers want, the shipowners build into these rates a reasonable enough profit to compensate for those days of part-cargo.

Apart from their inherent susceptibility to bureaucratic supervision, the other appeal of liners is that they account for roughly 50 per cent of all freight rates, although only 20 per cent or thereabouts of volume. There is a percentage, therefore, in going for control on the part of deprived developing countries. But it is a different story with the bulk trades; virtually all tankers, grain carriers, ore carriers and the like, as well as general cargo ships not in the Conferences, operate on the tramp principle. While the great majority of them ply pretty regular routes and are on charter for fixed customers, they are still much freer than liners to go where the rates are highest.

There is, in other words, a world of difference in the supervisory potential of the liner and the bulk trades. Yet with the compromise success of the Liner Code, the expectation at Manila was that the principles of cargo sharing could be extended from the carriage of mostly manufactured goods-where the Third World is a far greater importer than exporter-to that of raw materials, where it is an infinitely greater exporter than importer. The logic of extension applies well enough on the theoretical plane but is less obvious on the operational plane. This explains more than anything else why so little headway was made on the subject in Manila in May.
The very general picture so far painted should not be allowed to obscure some of the smaller cameos. Many developing countries have achieved carrying capacity in excess of the 40 per cent minimum without the benefit of protectionist international conventions, and a few of them without even the leg-up of protectionist domestic legislation. Also, a tiny handful of them have larger fleets flying their flags than do most Western countries, purely for the purpose of the fee income of registration of the tonnage. Liberia, Panama, Singapore and Cyprus are the ones that spring to mind, and formerly Honduras; these are widely referred to as the flags of convenience. Then again, a few developing countries earn substantial foreign exchange not from operating or registering ships, but from providing the crews. And a fourth group are rapidly building up the capacity actually to make ships, either for their own use or for international sale. Few of the oil producing countries feature in any of these categories.

These cameos can be said to complicate the general picture somewhat. A strict application of the 40:40:20 principle as a maximum rather than a minimum for cargo reservation in the liner trades and, for the sake of argument, in the bulk trades too, would in fact hit some developing countries, and let many developed countries go unscathed. And if the 40:40:20 principle covered not only the vessels but the people aboard them, such countries as the Philippines would be in genuine trouble, given the number of fine seamen she exports. And if the argument is lifted from the seagoing personnel to the onshore personnel, the Pandora's box of effective ship management under the new regime is well and truly opened. It will no doubt be remembered not only that Pandora got more than she expected, but that she could not shut the box again.

This whole international wrangle, with all its ramifications of equity, participation and profit, comes into sharp and sudden perspective when the obvious is stated: developing countries are not after the cargoes, they are after the ships. Under a regime where big international carriers such as the Norwegians, British, Greeks or Hong Kong Chinese, rapidly run up against their quota ceilings at their traditional ports of call and officially have to go away empty, the only way for such carriers to keep their ships working would be for them to do a deal. For the countries turning the excess tonnage away have very little tonnage of their own, and would like to acquire some. 
The key is the joint venture. A shipowner like Sir Y.K. Pao, the world's biggest, has a fleet approaching 200, more vessels than those possessed by around 35 developing countries together. Many South East Asian countries would like to meet their carrying capacity entitlement under 40: 40: 20, and often use his ships. So all that need be done is to switch flags on the required number for each country, give him 50 per cent of the holding company under each jurisdiction and then carry on as before. To suggest this is not to say that the World Wide Shipping Group-Sir Y.K. Pao's main company -is actively engaged in merger talks with nascent shipping groups the length and breadth of the Pacific; he has been singled out here only because of the size of his fleet. What is intended is to show the way things are probably going, and to add the comment that they would not be, were it not for the demands of cargo sharing as laid down by the 1974 Liner Code of Conduct.

No shipping company will give up the right to part of its assets if the market does not oblige it. The Third World knows that the market will not supply it with the ocean-going tonnage it wants, and so it must get it by other means. But will it benefit? As the most steady-nerved shipowner and the most uneasy shipping banker will agree, there is no causal relationship between having title to a ship, however beautifully and recently built, and getting profit out of it. Steady and respectable profits are obtainable from prudent ship management policies and careful marketing services when supply and demand are roughly in balance, though even in boom periods bad management and marketing can lose money on perfectly good ships and crew. But what is perhaps not so widely realised-and what thereby explains the element of emotion that enters the protests of many Third World negotiators against Western shipping in general-is that the big profits, the real money that gives the tycoons their airlines and luxury yachts, comes not from using ships, but from buying and selling them; and how are developing countries to get into that side of the business, should they want to?
It may be said in conclusion that on the long and weary road to a fairer distribution of the world's wealth, shipping is a useful milestone. The painting of new emblems on funnels and the hauling up of 100 new flags act as great psychological boosts to developing countries' selfconfidence, and taken in that light are welcome measures. But they will emerge as blessings more than a little mixed if they are seen as being sound economic initiatives in themselves. It cannot be stated too often by those who know-by those who have the ships and are one day to have to part with them-that running ships is not as easy as it looks. It has remained an independent low average profit industry throughout the postwar era while other forms of transport have become relatively expensive and increasingly subsidised. The main reason is that it has been competitive in the truest sense of the word. Bankruptcies have been common.

With ownership by Third World companies of a growing proportion of the world fleet, the role of the private sector is bound to decrease since the majority of enterprise in most developing countries is publicly owned and this will extend to the 50 per cent holdings in the wave of joint ventures that will flood the market as the 40: 40: 20 principle takes hold. There is no inherent reason why a state-owned enterprise should be less profitable than its privately-owned counterpart; it is just that within economies and between economies, this almost invariably seems to be the case, and there is little to indicate that the same will not also apply in world shipping. Without the incentive of private profit, the urge to cut costs to the bone quickly evaporates, and the customers lose out. It is a paradox that will stand the test of time that when the profit element is driven out of world shipping at one end, the low cost element will have been squeezed out at the other. So developing countries which desperately need to maximise the return on their investment in raw material production and sales, will see an erosion of profitability through higher transportation costs. And if that is seen as a summary too simplistic or too polemical-or both-for normal economic analysis, then the only counter is: wait and see. 